\title{
Separation and Recovery of Precious Metals from Leach Liquors of Spent Electronic Wastes by Solvent Extraction
}

\author{
Thi Hong Nguyen ${ }^{1,2}$, Lingyun Wang ${ }^{1}$, and Man Seung Lee ${ }^{1, *}$ \\ ${ }^{I}$ Department of Advanced Materials Science \& Engineering, Institute of Rare Metal, Mokpo National University, \\ Jeonnam 58554, Republic of Korea \\ ${ }^{2}$ College of Natural Sciences, Can Tho University, Can Tho City, Viet Nam
}

\begin{abstract}
Solvent extraction was employed to recover precious metals (Au (III), Pd (II) and Pt (IV)) from the leach solution of spent electronic wastes containing $\mathrm{Cu}$ (II), $\mathrm{Cr}$ (III) and Fe (III). First, pure Fe (III) and Au (III) were recovered by simultaneous extraction with Cyanex 923 followed by selective stripping with $\mathrm{HCl}$ and $\mathrm{Na}_{2} \mathrm{~S}_{2} \mathrm{O}_{3}$. Second, Pt (IV), Pd (II) and Cu (II) were extracted by Alamine 336 from the raffinate. After the removal of $\mathrm{Cu}$ (II) by stripping with weak $\mathrm{HCl}, \mathrm{Pd}$ (II) and $\mathrm{Pt}$ (IV) were separately stripped by controlling the concentration of thiourea in the mixture with $\mathrm{HCl}$. A process flow sheet for the separation of precious metals was proposed.
\end{abstract}

(Received August 18, 2016; Accepted November 2, 2016)

Keywords: gold, platinum, palladium, separation, solvent extraction

\section{INTRODUCTION}

Precious metals (PMs) such as gold ( $\mathrm{Au})$, platinum $(\mathrm{Pt})$ and palladium $(\mathrm{Pd})$ are widely used in many industrial areas, including jewelry, corrosion-resistant materials, and chemical catalysts, due to their specific properties [1,2]. However, increasing demand and the limited natural availability of these precious metals have stimulated efforts to develop effective separation processes to recover PMs from various secondary resources, such as waste printed circuit boards[3], anode slimes[4] and spent automobile catalysts [5,6]. However, in high concentration $\mathrm{HCl}$ in either the presence of an oxidizing agent or aqua regia, the secondary resources typically leach, leading to the complete dissolution of the precious metals, together with some impurities like Fe (III), $\mathrm{Cu}$ (II), $\mathrm{Cr}$ (III), Ni (II) and $\mathrm{Zn}$ (II)[6-8]. In order to recover the precious metals with high purity from the leach solution, solvent extraction[1,6,9-15], ion exchange[16-18] and precipitation[3,19,20] methods have subsequently been employed.

Many studies have reported on the extraction and

*Corresponding Author: Man Seung Lee

[Tel: +82-61-450-2492, E-mail: mslee@mokpo.ac.kr]

Copyright (c) The Korean Institute of Metals and Materials separation of Pt (IV) and Pd (II) using solvent extraction [5,6,21-28]. However, only a few works have reported on the separation of $\mathrm{Au}$ (I/III), Pt (IV) and Pd (II) from the leach liquors of secondary resources. To separate Au (I/III), Pt (IV) and Pd (II) from different solutions, a number of extractants, such as methyl iso-butylketone (MIBK)[29], tri-isobutyl phosphine sulfide (Cyanex 471X), a mixture of tetra trialkylphosphine oxides (Cyanex 923)[11,12], and tri-capryl methlyammonium chloride (Aliquat 336)[1] have been extensively. Although MIBK can selectively extract Au (III) from a chloride solution containing Fe (III), Ru (III), Os (III), $\mathrm{Pt}$ (IV), Pd (II) and Rh (III), the selectivity for $\mathrm{Au}$ (III) is not high and it is difficult to remove the impurities co-extracted into the MIBK by simple scrubbing [29]. Aliquat 336, Cyanex 923 and Cyanex 471X can selectively extract Au (III) over Pt (IV), Pd (II) and other metals from sulfuric acid/ hydrochloric acid solutions $[1,11,12]$. The main disadvantage of Cyanex 923, Cyanex 471 and Aliquat 336 is that the co-extraction of $\mathrm{Pt}$ (IV) and $\mathrm{Pd}$ (II) together with $\mathrm{Au}$ (III) is significant. According to most of the reported studies on the separation of $\mathrm{Au}$ (III), Pt (IV) and Pd (II) from different solutions, solvent extraction has some limitations, including low extraction rates and poor separation.

The objective of the present work was to develop a solvent 
Table 1. Compositions of real and diluted leaching solution

\begin{tabular}{lcccccc}
\hline \multicolumn{1}{c}{ Elements } & $\mathrm{Au}$ & $\mathrm{Pd}$ & $\mathrm{Pt}$ & $\mathrm{Fe}$ & $\mathrm{Cu}$ & $\mathrm{Cr}$ \\
\hline Actual leaching solution, mg/L & 346 & 646 & 45.7 & 122 & 545 & 33 \\
\hline $\begin{array}{l}\text { Diluted actual leaching } \\
\text { solution, } \mathrm{mg} / \mathrm{L}\end{array}$ & 63 & 128.5 & 9.2 & 26.5 & 122.4 & 6.9 \\
\hline
\end{tabular}

extracion process for separating and recovering $\mathrm{Au}$ (III), $\mathrm{Pd}$ (II) and Pt (IV) from the real leach solution of spent electronic wastes. The leach liquor of spent electronic wastes used in this work contained Au (III), Pt (IV) and Pd (II) together with some base metals, such as Fe (III), $\mathrm{Cu}$ (II) and $\mathrm{Cr}$ (III). In the acidic chloride solution, $\mathrm{Au}$ (III), $\mathrm{Pd}$ (II), $\mathrm{Pt}$ (IV), $\mathrm{Cu}$ (II) and Fe (III) exist as anionic species [30-33]. It is known that amines and neutral extractants can extract $\mathrm{Au}$ (III), Pt (IV), Pd (II) and Fe (III) from a hydrochloric acid solution [28,34]. Therefore, tri-octyl/decyl amine (Alamine 336) and neutral extractants (MIBK, TBP and Cyanex 923) were used for the separation of $\mathrm{Au}$ (III), Pt (IV), Pd (III) from the leach solution which contained $\mathrm{Fe}$ (III), $\mathrm{Cu}$ (II) and $\mathrm{Cr}$ (III). Complete separation of $\mathrm{Au}$ (III), Pd (II) and Pt (IV) from these leach solutions was achieved by extraction with Cyanex 923 and Alamine 336. For each extraction step, an optimum stripping condition was determined. On the basis of the results, a new process flow sheet for the separation of $\mathrm{Au}$ (III), Pt (IV), Pd (II) from leach solution by solvent extraction is proposed.

\section{EXPERIMENTAL}

Commercial extractants, such as tributyl phosphate (TBP, Yakuri Pure Chemical Co.), MIBK (Daejung Chemicals \& metals Co. LTD) and Alamine 336 (BASF Co.) and Cyanex 923 (Cytec) were used without further purification. Kerosene (Samchun Pure Chem. Co.) was used as a diluent. First, most of the metals present in the spent electronic wastes were dissolved in aqua regia. The acidity of the aqua regia was controlled by adding neutralizing agents to recover Au. After the recovery of $\mathrm{Au}$, the solution $\mathrm{pH}$ was around 0.7 , the solution composition is shown in Table 1 . Since there was insufficient quantity of real leach solution to conduct solvent extraction experiments, the $\mathrm{pH} 0.7$ leach solution was diluted with $\mathrm{HCl}$ solution of the same acidity, and then employed in the solvent extraction experiments (see Table 1).

Solvent extraction and stripping experiments were performed by mixing equal volumes $(10 \mathrm{~mL})$ of aqueous and organic phases for $30 \mathrm{~min}$ using a wrist action shaker (Burrel, model 75). After equilibrium, the two phases were separated using a separating funnel. All the experiments were performed at room temperature $\left(25 \pm 1{ }^{\circ} \mathrm{C}\right)$. Metal ion concentrations in the aqueous phase before and after extraction were determined by inductively coupled plasma-optical emission spectroscopy (ICP-OES; Spectro Arcos). The concentration of metals in the loaded organic phase was calculated by mass balance. The distribution coefficient (D) was calculated as the concentration of metal present in the organic phase to that present in the aqueous phase at equilibrium. The percentage of extraction and stripping is defined as Eqs. (1) and (2).

Extraction percentage $=\frac{\text { equilibrium mass of metal in the organic }}{\text { initial mass of metal in the aqueous before extraction }} \times 100$

Stripping percentage $=\frac{\text { equilibrium mass of metal in the aqueous after stripping }}{\text { initial mass of metal in the organic before stripping }} \times 100$

\section{RESULTS AND DISCUSSION}

\subsection{Selective extraction and separation of $A u$ and $\mathrm{Fe}$}

\subsubsection{Effect of neutral extractants}

In order to selectively extract $\mathrm{Au}$ (III), three kinds of neutral extractants (TBP, MIBK and Cyanex 923) were employed. The concentration of TBP/MIBK/Cyanex 923 was varied from 0.01 to $0.2 \mathrm{M}$ at the unity volume ratio of the two phases. Figs. 1-3 show the variation in the extraction percentage of $\mathrm{Au}$ (III), $\mathrm{Pd}$ (II), $\mathrm{Pt}$ (IV), $\mathrm{Cu}$ (II), $\mathrm{Cr}$ (III) and $\mathrm{Fe}$ (III) with extractant concentration. As seen in Figs. 1-3, the extraction efficiency of these metals with TBP and MIBK was much lower than that obtained with Cyanex 923. The extraction percentage of $\mathrm{Au}$ (III) was around $10 \%$ at any TBP/MIBK concentration range, while that of $\mathrm{Fe}$ (III), $\mathrm{Pd}$ (II), $\mathrm{Pt}(\mathrm{IV})$ and $\mathrm{Cu}(\mathrm{II})$ was negligible (see Figs. 1 and 2). In 


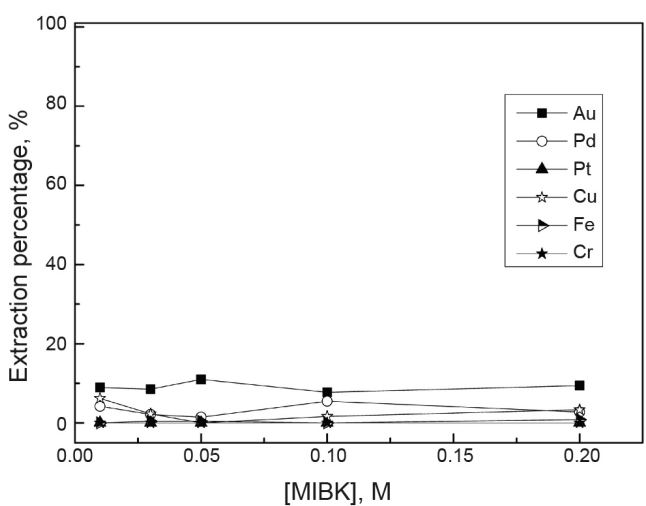

Fig. 1. Effect of MIBK concentration on extraction of $\mathrm{Au}, \mathrm{Pd}, \mathrm{Pt}$, $\mathrm{Cu}, \mathrm{Fe}$ and $\mathrm{Cr}$. Leach liquor, mg/L: Au-63, Pd-129, Pt-9.2, $\mathrm{Fe}-26.5, \mathrm{Cu}-122.4, \mathrm{Cr}-6.9 ;[\mathrm{MIBK}]=0.01-0.2 \mathrm{M} ; \mathrm{O} / \mathrm{A}=1$.

contrast, Cyanex 923 selectively extracted both $\mathrm{Au}$ (III) and Fe (III) better than the others (see Fig. 3). The extraction percentage of $\mathrm{Au}$ (III) and Fe (III) increased from 18 and 5\%, to 99.5 and $91.7 \%$, respectively, as the Cyanex 923 concentration was increased from 0.01 to $0.2 \mathrm{M}$. The co-extraction of Pd (II), Pt (IV) and Cu (II) was zero at any Cyanex 923 concentration range. In an acidic chloride solution of $\mathrm{pH}$ 0.7, $\mathrm{Au}$ (III), Pd (II) and Pt (IV) exist as anionic species, $\mathrm{AuCl}_{4}{ }^{-}, \mathrm{PdCl}_{4}{ }^{2-}$ and $\mathrm{PtCl}_{6}{ }^{2-}$ [30,33-36]. It has been reported that the formation of anionic species of $\mathrm{CuCl}_{4}{ }^{2-}$ and $\mathrm{FeCl}_{4}{ }^{-}$strongly depends on the concentration of chloride ions [32,33,37]. Although the anionic species of $\mathrm{Cu}$ (II) and Fe (III) like $\mathrm{CuCl}_{4}{ }^{2-}$ and $\mathrm{FeCl}_{4}{ }^{-}$can exist in the leach liquor employed in this work, some cationic and electrically neutral species, such as $\mathrm{Cu}^{2+}, \mathrm{FeCl}^{2+}, \mathrm{FeCl}_{2}{ }^{+}$, and $\mathrm{FeCl}_{3}$ can also exist [31-33,36]. Since MIBK, TBP and Cyanex 923 extract neutral species, the solvent extraction of Au (III) and Fe (III) by the above-mentioned neutral extractants can be represented as Eq. (3) $[10,31,32,37]$. In acidic leach liquors of $\mathrm{pH} 0.5$, most of the $\mathrm{Cr}$ (III) exits as $\mathrm{Cr}^{3+}[38]$ and thus the extraction of $\mathrm{Cr}$ (III) by MIBK, TBP and Cyanex 923 was negligible.

$$
\mathrm{M}^{\mathrm{n}^{-}} \text {(aq) }+\mathrm{nH}^{+} \text {(aq) }+\mathrm{mL}(\text { org })=\mathrm{HnMmL}_{(\text {org })}
$$

where $\mathrm{M}^{\mathrm{n}-}$ and $\mathrm{L}$ represent anionic species and the neutral extractant, respectively. The subscript aq and org represent the aqueous and organic phases, respectively.

The extraction efficiency of $\mathrm{Au}$ (III), Fe (III), Pt (IV), Pd

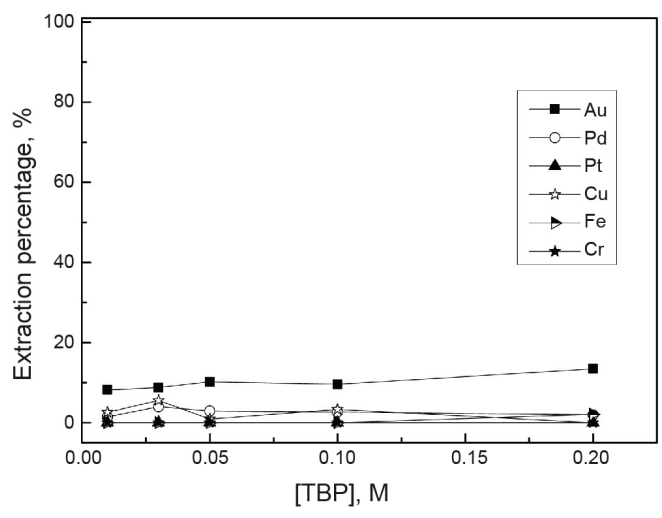

Fig. 2. Effect of TBP concentration on extraction of $\mathrm{Au}, \mathrm{Pd}, \mathrm{Pt}$, $\mathrm{Cu} \mathrm{Fe}$ and $\mathrm{Cr}$. Leach liquor, mg/L: Au-63, Pd-129, Pt-9.2, $\mathrm{Fe}-26.5, \mathrm{Cu}-122.4, \mathrm{Cr}-6.9$; [TBP $]=0.01-0.2 \mathrm{M} ; \mathrm{O} / \mathrm{A}=1$.

(II) and $\mathrm{Cu}$ (II) by these neutral extractants in the present study was in the order of MIBK $\approx \mathrm{TBP}<<$ Cyanex 923 for the same extractant concentration, which agrees well with the values reported in the literature $[39,40]$. The extraction order of these metals by MIBK, TBP and Cyanex 923 might be related to the extraction efficiency of hydrogen ions during the extraction process. Since the interaction between hydrogen ions and Cyanex 923 is much stronger than that with TBP/MIBK[41], Au (III) and Fe (III) were readily extracted by Cyanex 923 in our experimental conditions. The tendency of metal-chloro complexes of precious metals to be extracted by solvation mechanism is $\left[\mathrm{MCl}_{4}\right]^{-}>\left[\mathrm{MCl}_{6}\right]^{2-}>$ $\left[\mathrm{MCl}_{4}\right]^{2-}[1,28]$. Au (III) and Fe (III), which exist as $\mathrm{AuCl}_{4}{ }^{-}$ and $\mathrm{FeCl}_{4}{ }^{-}$, have lower charge densities than $\mathrm{Pd}$ (II), Pt (IV) and $\mathrm{Cu}(\mathrm{II})$, which exist as $\mathrm{PdCl}_{4}{ }^{2-}, \mathrm{PtCl}_{6}{ }^{2-}$ and $\mathrm{CuCl}_{4}{ }^{2-}$, respectively. It has been reported that a complex with a lower charge density attracts less water molecules, thus forming a smaller hydration shell[1,28], which has a positive effect on the formation of electrically neutral species in the solvation reaction. Therefore, the extraction percentage of $\mathrm{Au}$ (III) and Fe (III) was much higher than that of $\mathrm{Pt}$ (IV), $\mathrm{Pd}$ (II) and $\mathrm{Cu}$ (II) in the present work. According to the obtained results, 0.1 M Cyanex 923 was considered to be the optimum concentration to selectively extract both $\mathrm{Au}$ (III) and Fe (III) from the leach solution in the presence of $\mathrm{Pt}$ (IV), $\mathrm{Pd}$ (II), $\mathrm{Cu}$ (II) and $\mathrm{Cr}$ (III). 
Table 2. Effect of $\mathrm{HCl}$ concentration on stripping of $\mathrm{Au}$ and $\mathrm{Fe}$ from loaded Cyanex 923.

\begin{tabular}{ccc}
\hline \multirow{2}{*}[\mathrm{HCl}]{, $\mathrm{M}$} & \multicolumn{2}{c}{ Stripping percentage, \% } \\
\cline { 2 - 3 } & $\mathrm{Au}$ & $\mathrm{Fe}$ \\
\hline 0.01 & 0.33 & 3.6 \\
0.1 & 0.35 & 19.3 \\
0.2 & 0.31 & 40.5 \\
0.5 & 0.31 & 53 \\
\hline
\end{tabular}

Loaded organic: $60 \mathrm{mg} / \mathrm{L} \mathrm{Au}, 24 \mathrm{mg} / \mathrm{L} \mathrm{Fe} ;[\mathrm{HCl}]=0.01-1 \mathrm{M}$; [Cyanex 923] $=0.1 \mathrm{M}$

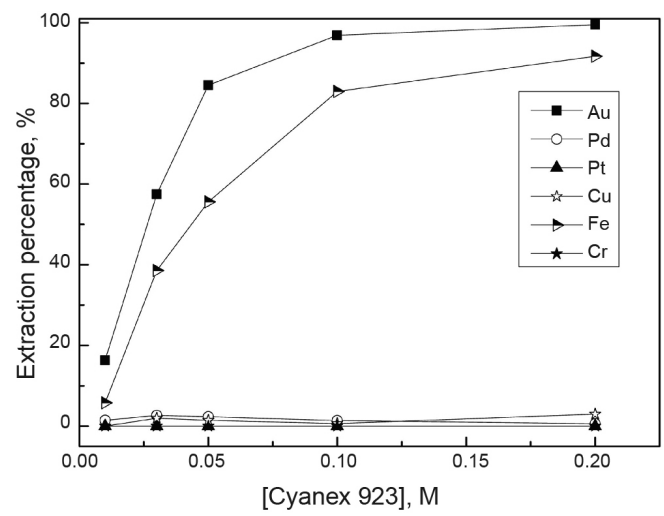

Fig. 3. Effect of Cyanex 923 concentration on extraction of $\mathrm{Au}$, $\mathrm{Pd}, \mathrm{Pt}, \mathrm{Cu}, \mathrm{Fe}$ and $\mathrm{Cr}$. Leach liquor, mg/L: Au-63, Pd-129, Pt-9.2, Fe-26.5, Cu-122.4, Cr-6.9; [Cyanex 923] = 0.01-0.2 M; $\mathrm{O} / \mathrm{A}=1$.

3.1.2. Separation of $A u$ (III) and Fe (III) from the loaded Cyanex 923 by stripping

$\mathrm{HCl}$ solutions with varying concentration from 0.01 to 0.5 $\mathrm{M}$ were employed as a stripping solution, and the obtained results are shown in table 2. The stripping percentage of Fe (III) increased from 3.6 to $53 \%$ with increasing $\mathrm{HCl}$ concentration from 0.01 to $0.5 \mathrm{M}$, while the stripping percentage of $\mathrm{Au}$ (III) was nearly zero. When Eq. (3) is responsible for the extraction of Fe (III) by Cyanex 923, the stripping reaction can be represented as

$$
\mathrm{HFeCl}_{4} \mathrm{~L}(\text { org })=\mathrm{L}(\text { org })+\mathrm{FeCl}_{4}^{-}(\mathrm{aq})+\mathrm{H}^{+}(\mathrm{aq})
$$

In this case, the stripping percentage of Fe (III) should decrease with the increase in $\mathrm{HCl}$ concentration in the stripping solution. In contrast, our data showed the reverse behavior. When $\mathrm{FeCl}_{3}$ is extracted by Cyanex 923 instead of $\mathrm{HFeCl}_{4}$, the stripping reaction by $\mathrm{HCl}$ solution can be represented as

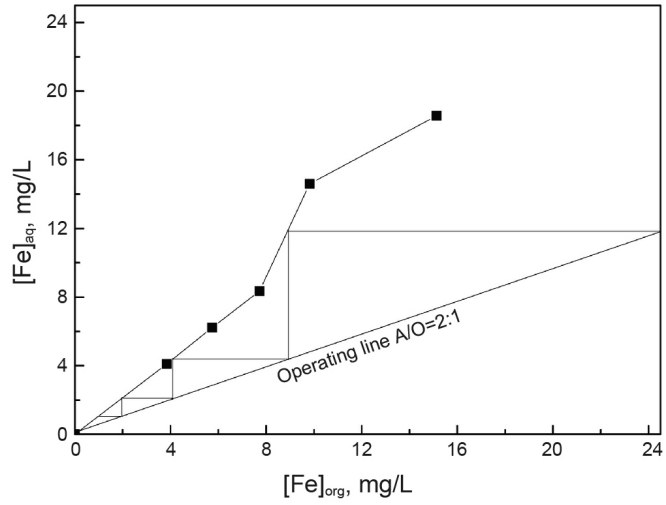

Fig. 4. Stripping isotherm of Fe from $0.1 \mathrm{M}$ Cyanex 923 using 0.5 $\mathrm{M} \mathrm{HCl}$. Loaded 0.1 M Cyanex 923:24 mg/L Fe; A/O = 1:3-5:5.

$$
\mathrm{FeCl}_{3} \mathrm{~L}(\text { org })+\mathrm{Cl}^{-}(\mathrm{aq})=\mathrm{L}(\text { org })+\mathrm{FeCl}_{4}^{-}(\mathrm{aq})
$$

Eq. (5) indicates that the stripping percentage of Fe (III) from the Cyanex 923 will increase as $\mathrm{HCl}$ concentration increases, which is in good agreement with our data. Therefore, in our extraction conditions it can be said that Fe (III) is extracted into Cyanex 923 as $\mathrm{FeCl}_{3}$.

Table 2 shows that Fe (III) in the loaded Cyanex 923 can be removed by stripping with $0.5 \mathrm{M} \mathrm{HCl}$ solution, leaving $\mathrm{Au}$ (III) in the stripped Cyanex 923. In order to construct a McCabe-Thiele diagram for the stripping of Fe (III) from the loaded Cyanex 923 using $0.5 \mathrm{M} \mathrm{HCl}$, the $\mathrm{A} / \mathrm{O}$ ratio was varied from 1:3 to 5:1. The loaded Cyanex 923 was prepared by contacting the aqueous solution with $0.1 \mathrm{M}$ Cyanex 923 at an $\mathrm{O} / \mathrm{A}$ ratio of unity. The loaded Cyanex 923 contained 60 $\mathrm{mg} / \mathrm{L} \mathrm{Au}$ (III) and $24 \mathrm{mg} / \mathrm{L} \mathrm{Fe}$ (III). The McCabe-Thiele diagram (Fig. 4) shows that four stages at an A/O of 2:1 can strip most of the Fe (III) from the loaded Cyanex 923. According to the batch simulation experiments with four stages of counter-current stripping, the $\mathrm{Fe}$ (III) was completely stripped from the loaded Cyanex 923 and the concentration of $\mathrm{Au}$ (III) in the stripping solution was negligible. After the stripping of Fe (III) from the loaded Cyanex 923, the stripped organic phase containing $60 \mathrm{mg} / \mathrm{L}$ $\mathrm{Au}$ (III) was used for further stripping experiments with $\mathrm{Au}$ (III) from the stripped Cyanex 923.

It has been reported that either $\mathrm{NaSCN}$ or $\mathrm{Na}_{2} \mathrm{~S}_{2} \mathrm{O}_{3}$ are effective for stripping $\mathrm{Au}$ (III) from a loaded organic [42,43]. 


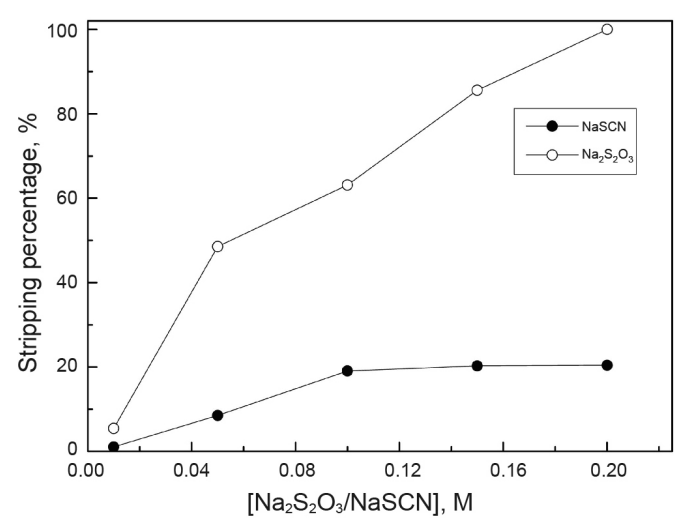

Fig. 5. Effect of $\mathrm{NaSCN} / \mathrm{Na}_{2} \mathrm{~S}_{2} \mathrm{O}_{3}$ concentration on stripping of $\mathrm{Au}$ from 0.1 M Caynex 923. Loaded 0.1 M Cyanex 923: $60 \mathrm{mg} / \mathrm{L}$ $\mathrm{Au} ;\left[\mathrm{NaSCN} / \mathrm{Na}_{2} \mathrm{~S}_{2} \mathrm{O}_{3}\right]=0.01-0.2 \mathrm{M} ; \mathrm{O} / \mathrm{A}=1: 1$.

Therefore, NaSCN and $\mathrm{Na}_{2} \mathrm{~S}_{2} \mathrm{O}_{3}$ solutions were used in the present stripping experiments. The concentrations of these stripping reagents were varied from 0.01 to $0.2 \mathrm{M}$ to strip $\mathrm{Au}$ (III) from the stripped Cyanex 923. Fig. 5 shows how the stripping percentage of $\mathrm{Au}$ (III) varies with the concentrarion of the stripping reagents. The stripping percentage of $\mathrm{Au}$ (III) was lower than $20 \%$ at any $\mathrm{NaSCN}$ concentration range, while it increased from $5 \%$ to $99 \%$ as the $\mathrm{Na}_{2} \mathrm{~S}_{2} \mathrm{O}_{3}$ concentration was increased from 0.01 to $0.2 \mathrm{M}$. It has been reported that $\mathrm{Au}(\mathrm{III})$ has a strong tendency to form complexes with $\mathrm{SCN}^{-}$and $\mathrm{S}_{2} \mathrm{O}_{3}{ }^{2-}$ [44-46]. Although the complex formation constant of $\mathrm{Au}$ (III) with $\mathrm{SCN}^{-}$is larger than that of $\mathrm{S}_{2} \mathrm{O}_{3}{ }^{2-}[44]$, the complex formation constants of $\mathrm{Au}$ (III) with these two ligands are so large that most of the $\mathrm{Au}$ (III) exists as either $\mathrm{Au}(\mathrm{SCN})_{4}{ }^{-}$or $\mathrm{Au}\left(\mathrm{S}_{2} \mathrm{O}_{3}\right)^{2-}$. The reason why the $\mathrm{Na}_{2} \mathrm{~S}_{2} \mathrm{O}_{3}$ solution led to a higher stripping percentage of $\mathrm{Au}(\mathrm{III})$ from the loaded Cyanex 923 than the NaSCN solution may be due to the reduction of $\mathrm{Au}$ (III) to $\mathrm{Au}$ (I) in the presence of the $\mathrm{Na}_{2} \mathrm{~S}_{2} \mathrm{O}_{3}$ solution. Since the sulfur in $\mathrm{S}_{2} \mathrm{O}_{3}{ }^{2-}$ can be oxidized to a higher oxidation state, $\mathrm{Au}$ (III) can be reduced to $\mathrm{Au}(\mathrm{I})$ in the stripping solution [45]. When this redox reaction occurs in the stripping solution, the stripping reaction of $\mathrm{Au}$ (III) from the loaded Cyanex 923 will be facilitated. The reaction occurring during the stripping with $\mathrm{Na}_{2} \mathrm{~S}_{2} \mathrm{O}_{3}$ solution can be represented as

$$
\mathrm{AuCl}_{4}{ }^{-}+4 \mathrm{~S}_{2} \mathrm{O}_{3}{ }^{2-}=\mathrm{Au}\left(\mathrm{S}_{2} \mathrm{O}_{3}\right) 2^{3-}+\mathrm{S}_{4} \mathrm{O}_{6}{ }^{2-}+4 \mathrm{Cl}^{-}
$$

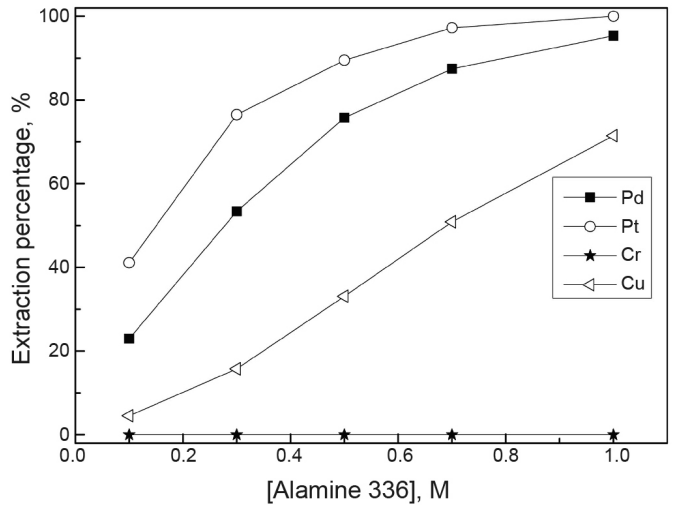

Fig. 6. Effect of Alamine 336 concentration on extraction of Pd, $\mathrm{Pt}, \mathrm{Cu}$ and $\mathrm{Cr}$ by Alamine 336. Raffinate, $\mathrm{mg} / \mathrm{L}: \mathrm{Pd}-128.5$, Pt-9.2, $\mathrm{Cu}-122.4, \mathrm{Cr}-6.9$; [Alamine 336] $=0.1-1 \mathrm{M} ; \mathrm{O} / \mathrm{A}=1$.

\subsection{Separation of Pd (II), Pt (IV) and Cu (II)}

\subsubsection{Effect of Alamine 336 concentration}

In general, amines are effective for extracting both Pt (IV) and $\mathrm{Pd}$ (II) from concentrated $\mathrm{HCl}$ solution [28]. Therefore, Alamine 336 was used in the present work to extract Pt (IV) and $\mathrm{Pd}$ (II) from the $\mathrm{Au}$ (III) and $\mathrm{Fe}$ (III) free raffinate. The concentration of Alamine 336 was varied from 0.1 to $1 \mathrm{M}$. The composition of the $\mathrm{Au}$ (III) and Fe (III) free raffinate was as follows: $\mathrm{Pd}$ (II)-128.5 mg/L, Pt (IV)-9.2 mg/L, Cu (II)-122.4 mg/L, and Cr (III)-6.9 mg/L. Figure 6 shows the variation in extraction percentage of $\mathrm{Pd}$ (II), $\mathrm{Pt}$ (IV), $\mathrm{Cu}$ (II) and $\mathrm{Cr}$ (III) with Alamine 336 concentration. The extraction percentage of $\mathrm{Pd}$ (II), $\mathrm{Pt}$ (IV) and $\mathrm{Cu}$ (II) increased as Alamine 336 concentration increased from 0.1 to $1 \mathrm{M}$ (see Fig. 6). The extraction order of these metals by Alamine 336 was $\mathrm{Pt}(\mathrm{IV})>\mathrm{Pd}$ (II) $>\mathrm{Cu}$ (II). These results agree well with the reported results that the extraction percentage of precious metals by amines was in the order of $\left[\mathrm{MCl}_{4}\right]^{-}>\left[\mathrm{MCl}_{6}\right]^{2-}>$ $\left[\mathrm{MCl}_{4}\right]^{2-}[1,28]$. Because the $\mathrm{PtCl}_{6}{ }^{2-}$ has the lowest charge density, the extraction percentage of $\mathrm{PtCl}_{6}{ }^{2-}$ by Alamine 336 was higher than that of $\mathrm{PdCl}_{4}{ }^{2-}$ and $\mathrm{CuCl}_{4}{ }^{2-}$. The extraction percentage of $\mathrm{Cr}$ (III) was zero at any Alamine 336 concentration. It can be concluded that $1 \mathrm{M}$ Alamine 336 can extract most of the $\mathrm{Pd}$ (II), Pt (IV) and $\mathrm{Cu}$ (II), while leaving $\mathrm{Cr}$ (III) in the raffinate.

\subsubsection{Effect of O/A ratio}

In order to investigate the effect of $\mathrm{O} / \mathrm{A}$ ratio on the 


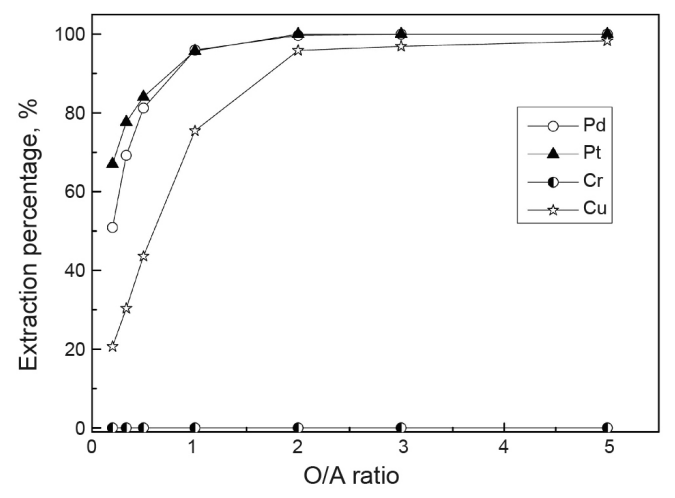

Fig. 7. Effect of $\mathrm{O} / \mathrm{A}$ ratio on extraction of $\mathrm{Pd}, \mathrm{Pt}, \mathrm{Cu}, \mathrm{Cr}$ by Alamine 336. Raffinate, mg/L: Pd-128.5, Pt-9.2, Cu -122.4, Cr-6.9; $[$ Alamine 336] $=1 \mathrm{M} ; \mathrm{O} / \mathrm{A}=1: 5-5: 1$.

extraction of $\mathrm{Pd}$ (II), Pt (IV), Cu (II) and $\mathrm{Cr}$ (III) by $1 \mathrm{M}$ Alamine 336 , various $\mathrm{O} / \mathrm{A}$ ratios from $1: 5$ to $5: 1$ were employed with the $\mathrm{Au}$ (III) and $\mathrm{Fe}$ (III) free raffinate containing $\mathrm{Pd}$ (II)-128.5 mg/L, Pt (IV)-9.2 mg/L, Cu (II) $-122.4 \mathrm{mg} / \mathrm{L}$, and $\mathrm{Cr}$ (III)-6.9 mg/L. Figure 7 shows that the $\mathrm{O} / \mathrm{A}$ ratio strongly affected the extraction of $\mathrm{Pd}$ (II), Pt (IV) and $\mathrm{Cu}$ (II). The extraction percentage of Pd (II), Pt (IV) and $\mathrm{Cu}$ (II) increased steadily and reached a peak at $\mathrm{O} / \mathrm{A}=2: 1$, while $\mathrm{Cr}$ (III) was not extracted at all at any O/A ratio. The obtained results indicate that an $\mathrm{O} / \mathrm{A}$ ratio of higher than 1 is necessary to completely extract Pd (II), Pt (IV) and $\mathrm{Cu}$ (II).

\subsubsection{Separation of Pd (II), Pt (IV) and Cu (II) by stripping}

According to the distribution of copper (II), cationic and neutral species of $\mathrm{Cu}$ (II), such as $\mathrm{Cu}^{2+}, \mathrm{CuCl}^{+}$, and $\mathrm{CuCl}_{2}$ exist in a moderate acid solution and these species cannot be extracted by amines [32,46]. Thus $\mathrm{HCl}$ solutions with 0.01-0.3 $\mathrm{M}$ were used for stripping experiments in this study. The loaded Alamine 336 was prepared by contacting the raffinate containing $\mathrm{Pd}$ (II)-128.5 mg/L, Pt (IV)-9.2 mg/L, Cu (II)-122.4 mg/L and Cr (III)-6.9 mg/L with $1 \mathrm{M}$ Alamine 336 at an $\mathrm{O} / \mathrm{A}$ ratio of unity. The loaded Alamine 336 contained Pd (II)-126 mg/L, Pt (IV)-8.9 mg/L and Cu (II)-88.9 mg/L. In the stripping experiments, the volume ratio of the two phases was controlled to unity. Table 3 shows the variation in stripping percentage of $\mathrm{Pd}$ (II), $\mathrm{Pt}$ (IV) and $\mathrm{Cu}$ (II) with $\mathrm{HCl}$ concentration. The stripping percentage of $\mathrm{Cu}$ (II) decreased from 100 to $96 \%$ with the increase in $\mathrm{HCl}$ concentration from
Table 3. Effect of $\mathrm{HCl}$ concentration on stripping of $\mathrm{Cu}$ from loaded Alamine 336.

\begin{tabular}{ccc}
\hline \multirow{2}{*}[\mathrm{HCl}]{, $\mathrm{M}$} & \multicolumn{2}{c}{ Stripping percentage, $\%$} \\
\cline { 2 - 3 } & $\mathrm{Pt} / \mathrm{Pd}$ & $\mathrm{Cu}$ \\
\hline 0.01 & & 99.9 \\
0.05 & No stripping & 97.8 \\
0.1 & & 97.2 \\
0.3 & & 96.9 \\
\hline
\end{tabular}

Loaded organic: $126 \mathrm{mg} / \mathrm{L} \mathrm{Pd}, 8.9 \mathrm{mg} / \mathrm{L} \mathrm{Pt}, 88.9 \mathrm{mg} / \mathrm{L} \mathrm{Cu}$; [HCl] = 0.01-0.3 M; [Alamine 336] = $1 \mathrm{M}$.

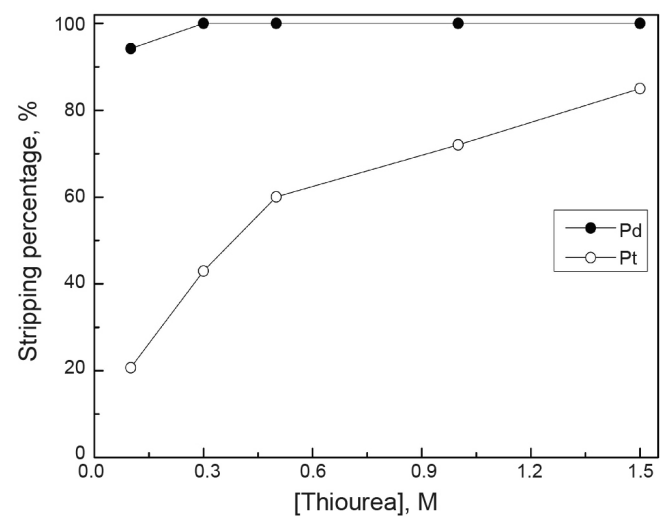

Fig. 8. Effect of thiourea concentration on stripping of $\mathrm{Pd}$ and $\mathrm{Pt}$ from Alamine 336 by the mixture of $0.5 \mathrm{M} \mathrm{HCl}$ and thiourea. Loaded $1 \mathrm{M}$ Alamine 336, mg/L: Pd-126, Pt-8.9; Stripping reagent $=0.5 \mathrm{M} \mathrm{HCl}+0.1-1.5 \mathrm{M}$ thiourea; $\mathrm{O} / \mathrm{A}=1$.

0.01 to $0.3 \mathrm{M}$, while no Pd (II) and Pt (IV) was stripped in this $\mathrm{HCl}$ concentration range. When $\mathrm{HCl}$ concentration was 0.01-0.3 M, anionic species of Pt (IV) and Pd (II), such as $\mathrm{PtCl}_{6}{ }^{2-}, \mathrm{PtCl}_{4}{ }^{2-}, \mathrm{PdCl}_{4}{ }^{2-}$ and $\mathrm{PdCl}_{3}{ }^{-}$still exist in the solution[35], which can be extracted by amines, resulting in the low stripping of Pt (IV) and Pd (II) from the loaded Alamine 336. The obtained results indicate that $\mathrm{Cu}$ (II) can be removed from the loaded Alamine 336 by selective stripping over Pt (IV) and Pd (II) with $0.01 \mathrm{M} \mathrm{HCl}$ solution.

In the stripping of Pt (IV) and Pd (II) from amines, a mixture of thiourea and $\mathrm{HCl}$ is considered to be the optimum stripping reagent, due to its high stripping efficiency $[5,21,23,27]$. Previous studies have reported that the concentration of thiourea in the mixture with the $\mathrm{HCl}$ strongly affects the stripping and separation efficiency for Pd (II) and Pt (IV) from Aliquat 336 and Alamine 308 [27,28]. Therefore, in order to achieve the optimum condition for stripping and separating Pd (II) and Pt (IV) from the stripped 


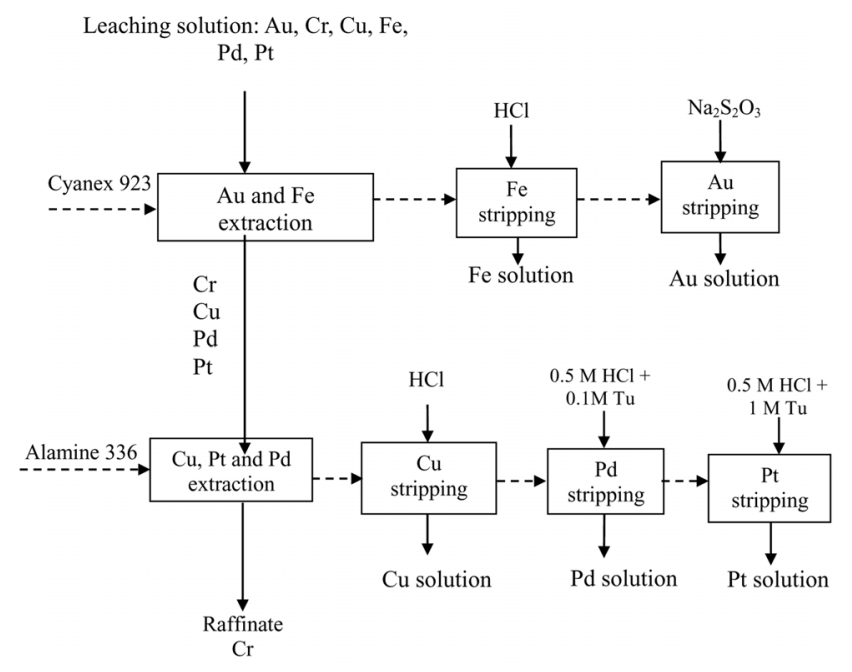

Fig. 9. Conceptual flowsheet for the separation and recovery of $\mathrm{Au}, \mathrm{Pd}$ and Pt from real leaching solution by solvent extraction

Alamine 336 containing Pd (II)-126 mg/L and Pt (IV)-8.9 $\mathrm{mg} / \mathrm{L}$ using a mixture of $\mathrm{HCl}$ and thiourea, the concentration of $\mathrm{HCl}$ was fixed at $0.5 \mathrm{M}$ and that of thiourea in the mixture was varied from 0.1 to $1.5 \mathrm{M}$. Figure 8 shows the variation in stripping percentage of $\mathrm{Pd}$ (II) and Pt (IV) according to thiourea concentration. Most of the Pd (II) was stripped from the loaded Alamine 336 at any thiourea concentration range in the $0.5 \mathrm{M} \mathrm{HCl}$ solution. However, the stripping percentage of Pt (IV) increased from $20 \%$ to $85 \%$ when the thiourea concentration was increased from 0.1 to $1.5 \mathrm{M}$. The obtained results agree well with the results reported in the literature, which indicate that Pd (II) can be selectively stripped over Pt (IV) from loaded amines using a mixture of thiourea and $\mathrm{HCl}$ [21,23,27,28]. According to Fig. 8, the mixture of $0.1 \mathrm{M}$ thiourea and $0.5 \mathrm{M} \mathrm{HCl}$ can be considered the optimum condition for selectively stripping Pd (II) over Pt (IV) from loaded Alamine 336. The Pt (IV) remaining in the stripped Alamine 336 can be stripped by increasing the thiourea concentration in the $0.5 \mathrm{M} \mathrm{HCl}$ solution.

A proposed process for the selective extraction and separation of $\mathrm{Au}$ (III), Pt (IV) and Pd (II) from the real leach liquors of spent electronic wastes in the presence of $\mathrm{Cu}$ (II), Fe (III) and Cr (III) by Cyanex 923 and Alamine 336 is presented in Fig. 9. Compared to the process for separating of $\mathrm{Au}$ (III), Pt (IV) and Pd (II) from sulfuric acid solution by Cyanex 923[11], the advantage of the current process lies in the fact that no Pt (IV) and Pd (II) were co-extracted by Cyanex 923, and thus the recovery step of Au from the loaded Cyanex 923 was very simple. Using this process, pure $\mathrm{Au}$ (III), Pt (IV) and Pd (II) solutions can be recovered from the leach solution of spent electronic wastes.

\section{CONCLUSION}

Solvent extraction experiments were performed to recover precious metals such as $\mathrm{Au}$ (III), Pd (II) and Pt (IV) from the real leach solution of spent electronic wastes which contained Fe (III), $\mathrm{Cu}$ (II) and $\mathrm{Cr}$ (III). First, an extraction of the $\mathrm{pH} 0.7$ leach solution using Cyanex 923 led to the complete extraction of $\mathrm{Au}$ (III) and Fe (III), leaving the other metals in the raffinate. Only Fe (III) could be removed from the loaded Cyanex 923 by stripping with dilute $\mathrm{HCl}$ solution, leaving most of the Au (III) in the stripped Cyanex 923. Pure Au (III) was recovered by stripping of the stripped Cyanex 923 with $\mathrm{Na}_{2} \mathrm{~S}_{2} \mathrm{O}_{3}$ solution. Second, extraction of the $\mathrm{Au}$ (III) and $\mathrm{Fe}$ (III) free raffinate with Alamine 336 resulted in the selective extraction of $\mathrm{Pt}$ (IV) and $\mathrm{Pd}$ (II) as well as $\mathrm{Cu}$ (II). $\mathrm{Cu}$ (II) from the loaded Alamine 336 was selectively stripped over Pd (II) and Pt (IV) by dilute $\mathrm{HCl}$ solution. After the separation of $\mathrm{Cu}$ (II) from the loaded Alamine 336, the Pd (II) and Pt (IV) were separately stripped by controlling thiourea concentration in a mixture with $\mathrm{HCl}$ solution. Based on the obtained results, a process flow sheet for the recovery of $\mathrm{Au}$ (III), Pd (II) and Pt (IV) with high purity from the leach liquors of spent electronic wastes was proposed.

\section{ACKNOWLEDGEMENTS}

This work was supported by the Global Excellent Technology Innovation of the Korea Institute of Energy Technology Evaluation and Planning (KETEP), granted financial resource from the Ministry of Trade, Industry \&Energy, Republic of Korea. (No.20165010100810)

\section{REFERENCES}

1. W. Wei, C. Cho, S. Kim, M. H. Song, J. K. Bediako and 
Y. S. Yun, J. Mol. Liq. 216, 18 (2016).

2. S. K. Oh, Y. J. Kim, M. Y. Shon and H. S. Kwon, Met. Mater. Int. 22, 781 (2016).

3. A. Behnamfard, M. M. Salarirad and F. Veglio, Waste Manage. 33, 2354 (2013).

4. R. Ranjbar, M. Naderi, H. Omidvar and G. H. Amoabediny, Hydrometallurgy 143, 54 (2014).

5. J. Y. Lee, B. Raju, B. N. Kumar, J. R. Kumar, H. K. Park and B. R. Reddy, Sep. Purif. Technol. 73, 213 (2010).

6. B. R. Reddy, B. Raju, J. Y. Lee and H. K. Park, J. Hazard. Mater. 180, 253 (2010).

7. C. J. Oh and S. O. Lee, Air Waste Manage. Assoc. 53, 897 (2003).

8. J. Cui and L. Zhang, J. Hazard. Mater. 158, 228 (2008).

9. E. A. Mowafy and D. Mohamed, Sep. Purif. Technol. 167, 146 (2016).

10. N. Sadeghi and E. K. Alamdari, Miner. Eng. 85, 34 (2016).

11. B. Gupta and I. Singh, Hydrometallury 134, 11 (2013).

12. B. Gupta, I. Singh and H. Mahandra, Sep. Purif. Technol. 132, 102 (2014).

13. Y. Liu, H. S. Jeon and M. S. Lee, Korean J. Met. Mater. 54, 592 (2016).

14. L. Y. Wang and M. S. Lee, Korean J. Met. Mater. 54, 97 (2016).

15. Y. Liu, H. S. Jeon and M. S. Lee, Met. Mater. Int. 21, 944 (2015)

16. R. Al-Nerey, Z. Hariri and J. A. Hilal, Microchem. J. 75, 169 (2003).

17. H. Zhang and D. B. Dreisinger, Hydrometallurgy 72, 225 (2004).

18. H. Murakami, S. Nishihama and K. Yoshizuka, Hydrometallurgy 157, 194 (2015).

19. X. Guo, J. Liu, H. Qin, Y. Liu, Q. Tian and D. Li, Hydrometallurgy 156, 199 (2015).

20. I. Birloaga and F. Veglio, J. Environ. Chem. Eng. 4, 20 (2016).

21. B. Raju, J. R. Kumar, J. Y. Lee, H. S. Kwonc, M. L. Kantam, and B.R. Reddy, J. Hazard. Mater. 227-228, 142 (2012).

22. M. V. Rane and V. Venugopal, Hydrometallurgy 84, 54 (2006).

23. M. K. Jha, D. Gupta, J. C. Lee, V. Kumar and J. Jeong, Hydrometallurgy 142, 60 (2014).
24. B. Swain, J. Jeong, S. K. Kim and J. C. Lee, Hydrometallurgy 104, 1 (2010).

25. S. V. Bandekar and P. M. Dhadke, Sep. Purif. Technol. 13, 129 (1998).

26. P. P. Sun and M. S. Lee, Hydrometallurgy 109, 181 (2011).

27. T. H. Nguyen, C. H. Sonu and M. S. Lee, J. Ind. Eng. Chem. 32, 238 (2015).

28. T. H. Nguyen, B. N. Kumar and M. S. Lee, Korean J. Chem. Eng. 33, 2684 (2016).

29. J. Rydberg, M. Cox, C. Musikas and G. R. Choppin, Solvent Extraction Principles and Practice, second ed, pp. 480-485, Marcel Dekker, New York (2004).

30. S. Martinez, P. Navarro, A. M. Sastre and F. J. Alguacil, Hydrometallurgy 43, 1 (1996).

31. R. K. Mishra, P. C. Rout, K. Sarangi and K. C. Nathsarma, Hydrometallurgy 104, 298 (2010).

32. S. Mishra and N. Devi, Hydrometallurgy 107, 29 (2011).

33. A. Cieszynska and M. Wisniewski, Sep. Purif. Technol. 80, 385 (2011).

34. T. H. Nguyen, C. H. Sonu and M. S. Lee. Hydrometallury 164, 71 (2016).

35. C. Colombo, C. J. Oates, A. J. Monhemius and J. A. Plant, Geochem.: Explor. Environ. Anal. 8, 1 (2008).

36. M. S. Lee and K. J. Lee, Hydrometallurgy 80, 163 (2005).

37. A. Borowiak-Resterna and J. Szymanowski, J. Radioanal. Nucl. Chem. 246, 657 (2000).

38. A. A. Nayl and H. F. Aly, Trans. Nonferrous Met. Soc. China 25, 4183 (2015).

39. F. J. Alguacil, Hydrometallurgy 66, 117 (2002).

40. R. K. Mishra, P. C. Rout, K. Sarangi and K. C. Nathsarma, Hydrometallurgy 104, 298 (2010).

41. K. Sarangi, E. Padhan, P. V. R. B. Sarma, K. H. Park and R P. Das, Hydrometallurgy 84, 125 (2006).

42. J. Lee, M. S. Safarzadeh, M. S. Moats, J. D. Miller and K. M. Levier, Hydrometallurgy 113-114, 31 (2012).

43. V. T. Nguyen, J. C. Lee, J. Jeong, B. S. Kim, G. Cote and A. Chagnes, Ind. Eng. Chem. Res. 54, 1350 (2015).

44. P. Johnston, N. Carthey and G. J. Hutchings, J. American Chem. Soc. 137, 15448 (2015).

45. M. L. Machesky, W. O. Andrade and A. W. Rose, Geochim. Cosmochim. Ac. 55, 769 (1990).

46. L. I. Elding, A. B. Groning and O. Groning, J. Chem. Soc. Dalton Trans. 5, 1093 (1981). 